\title{
Interaction of Left Ventricular Relaxation and Filling During Early Diastole in Human Subjects
}

\author{
PAOLO FIORETTI, MD \\ RONALD W. BROWER, PhD \\ GEERT T. MEESTER, MD \\ PATRICK W. SERRUYS, MD
}

Rotterdam, The Netherlands
From the Department of Cardiology, Thoraxcentrum, Erasmus University, Rotterdam, and the Intenuniversity Cardiology Institute, Amsterdam, The Netherlands. Manuscript received November 12 1979; revised manuscript received January 29, 1980, accepted March 4, 1980.

Address for reprints: Ronald W. Brower, Ee 2328, Erasmus University, pob 1738,3000 DR, Rotterdam, The Netherlands.
Seventeen patlents with coronary artery disease were studied with cineangiography and simultaneous tip manometry at resting heart rate and submaximal tachycardia induced by atrial pacing. During early diastole, defined as the interval from the opening of the mitral valve to the point of minimal left ventricular pressure, 20 percent of total ventricular filling took place at resting heart rate, but 62 percent occurred during tachycardia. Minimal pressure was signiflcantly correlated with the time constant of pressure decay during the Isovolumic phase $(r=0.75$ at resting heart rate and $r=0.81$ during tachycardla). The measured minimal pressure could be predicted by extrapolating the exponentlal decay of ventricular isovolumic pressure to the time of occurrence of the minimal pressure, which occurred on average 2.7 time constants from the peak negative rate of change of pressure. Al resting heart rate the time constant of relaxation was inversely correlated with ventricular inflow volume ( $r$ $=-0.64)$ and inflow rate $(r=-0.72)$. It is concluded that left ventricular relaxation has a relevant role in early dlastollc pressure-volume relations and increases during tachycardla.

During the earliest part of diastole, after the opening of the mitral valve, the left ventricle fills while the pressure continues to decrease. It has been reported in animals and in human subjects that a large proportion of left ventricular filling takes place ${ }^{1-5}$ and that the filling rate peaks within this short time interval. ${ }^{2}$ These observations suggest that ventricular relaxation extends beyond the isovolumic phase, makes a relevant contribution to ventricular filling and influences pressure-volume relations during early diastole. These conclusions have been partly corroborated by the recent studies in dogs by Weisfeldt et al. ${ }^{6,7}$

The present study was undertaken to investigate in human beings the extension of left ventricular relaxation in diastole and to assess its relevance to early diastolic left ventricular pressure and inflow at resting heart rate and during submaximal tachycardia induced by atrial pacing.

\section{Methods}

Patients: Diagnostic cardiac catheterization was performed in 17 adults whose ages ranged from 42 to 63 years (mean 51 ); 15 were men and 2 women. All medications (such as digoxin or beta blocking agents) were withdrawn 36 hours before catheterization. No tranquilizers or long-acting nitrates were given as premedication. Heparin (50 mg intravenously) was given at the beginning of the investigation. All patients had stable angina pectoris and proved coronary artery disease. Catheterization data (regional wall motion, coronary angiographic findings and graft patency, when appropriate) together with electrocardiographic data are shown in Table I. Six patients had a previous myocardial infarction (anterior in 2 and inferior in 4) and 11 had previous coronary bypass graft surgery. In no case was mitral insufficiency or left ventricular dyskinesia detected.

Study protocol: The study protocol included two cineventriculograms at 50 frames/s, the first at resting heart rate and the second at submaximal tachycardia 
TABLE I

Summary of Anglographic and Electrocardlographic Findings

\begin{tabular}{|c|c|c|c|c|}
\hline \multirow[b]{2}{*}{ Case } & \multicolumn{3}{|c|}{ Angiographic Data } & \multirow[b]{2}{*}{ ECG } \\
\hline & Regional Wall Motion & $\begin{array}{c}\text { Coronary Arteries } \\
\text { (\% stenosis) }\end{array}$ & CABG Status & \\
\hline $\begin{array}{r}1 \\
2 \\
3 \\
4 \\
5 \\
6 \\
7 \\
8 \\
9 \\
10 \\
11 \\
12 \\
13 \\
14 \\
15 \\
16 \\
17\end{array}$ & $\begin{array}{l}\text { Normal } \\
\text { Apex, hypo } \\
\text { Inf, hypo } \\
\text { Inf, hypo } \\
\text { Normal } \\
\text { Normal } \\
\text { Ant-lat, hypo; apex, akin } \\
\text { Hypo (diffuse) } \\
\text { Normal } \\
\text { Ant-lat, hypo; inf, hypo } \\
\text { Normal } \\
\text { Inf and sept, hypo } \\
\text { Ant-inf, hypo } \\
\text { Normal } \\
\text { Normal } \\
\text { Normal } \\
\text { Ant-inf and sept, hypo }\end{array}$ & 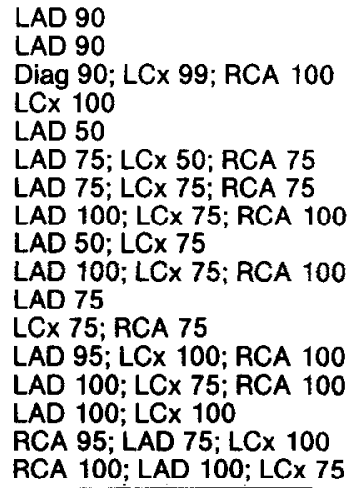 & $\begin{array}{l}\ldots \\
\ldots \\
\ldots \\
\ldots \\
\text {. } \\
\text { LAD patent; LCx occl; RCA occl } \\
\text { LAD patent; LCx patent; RCA patent } \\
\text { LAD occl; LCx occl } \\
\text { LAD patent; LCx occl; RCA patent } \\
\text { LAD patent } \\
\text { LCx patent; RCA patent } \\
\text { LAD patent; LCx patent } \\
\text { LAD occl; LCx OCCl; RCA patent } \\
\text { LAD patent; LCx patent } \\
\text { RCA patent; LAD occl; LCx occl } \\
\text { RCA patent; LAD patent; LCx patent }\end{array}$ & $\begin{array}{l}\text { Norma } \\
\text { Norma } \\
\text { Inf MI } \\
\text { Norma } \\
\text { Norma } \\
\text { Norma } \\
\text { Ant MI } \\
\text { Inf MI } \\
\text { Norma } \\
\text { Inf MI } \\
\text { Norma } \\
\text { Norma } \\
\text { Norma } \\
\text { Norma } \\
\text { Ant MI } \\
\text { Norma } \\
\text { Inf MI }\end{array}$ \\
\hline
\end{tabular}

akin = akinetic; ant $=$ anterior; $C A B G=$ coronary arterial bypass graft; hypo = hypokinetic; inf $=$ inferior wall; $L A D=$ left anterior descending coronary artery; lat = lateral wall; $L C x=$ left circumflex artery; $M I=$ myocardial infarct; occl $=$ occluded; $R C A=$ right coronary artery; sept $=$ septum; ... = grafting not performed.

during atrial pacing. No patient complained of angina during pacing. The angiograms were taken at midinspiration, and particular attention was paid to avoid the Valsalva maneuver. The second ventriculugram was obtained at least 15 minutes later and not until ventricular pressure returned to the values obtained at rest. In eight patients a biplane (right anterior oblique and left anterior oblique) and in nine a single plane (right anterior oblique) technique was used. In every patient a left anterior oblique angiogram was obtained at resting heart rate.
The left ventricular volumes were measured by Simpson's rule, using automatic contour detection ${ }^{8,9}$ for the single plane films and the area-length method for the biplane films. No regression equation was used. The correlation coefficient between the two methods for 64 volume measurements in eight patients was 0.96 with a standard error of the estimate of $11 \mathrm{ml}$. A high fidelity left ventricular pressure tracing was recorded simultaneously with the angiogram with use of an F8 Angio Millar microtip catheter at full scale and high gain.

\section{TABLE ॥}

Left Ventricular Pressure Measurements and Derived Indexes

\begin{tabular}{|c|c|c|c|c|c|c|c|c|c|c|c|c|c|c|c|c|}
\hline \multirow[b]{2}{*}{ Case } & \multicolumn{2}{|c|}{$\begin{array}{c}\mathrm{HR} \\
\left(\min ^{-1}\right)\end{array}$} & \multicolumn{2}{|c|}{$\begin{array}{c}\text { PkSP } \\
(\mathrm{mm} \mathrm{Hg})\end{array}$} & \multicolumn{2}{|c|}{$\begin{array}{c}\text { ESP } \\
(\mathrm{mm} \mathrm{Hg})\end{array}$} & \multicolumn{2}{|c|}{$\underset{(\mathrm{mm} \mathrm{Hg})}{\text { Pmin }}$} & \multicolumn{2}{|c|}{$\begin{array}{c}\text { EDP } \\
(\mathrm{mm} \mathrm{Hg})\end{array}$} & \multicolumn{2}{|c|}{$\underset{(\mathrm{ms})}{\mathrm{T}}$} & \multicolumn{2}{|c|}{$\begin{array}{l}\text { Peak } \\
\mathrm{dP} / \mathrm{dt} \\
(\mathrm{mm} \mathrm{Hg} / \mathrm{s})\end{array}$} & \multicolumn{2}{|c|}{$\begin{array}{c}\text { Peak Negative } \\
\text { dP/dt } \\
\text { (mm Hg/s) }\end{array}$} \\
\hline & $\mathbf{R}$ & $P$ & $\mathbf{R}$ & $P$ & $\mathrm{R}$ & $P$ & $\mathrm{R}$ & $\mathbf{P}$ & $\mathrm{R}$ & $P$ & $R$ & $P$ & $\mathrm{R}$ & $\mathbf{P}$ & $\mathrm{R}$ & $P$ \\
\hline $\begin{array}{c}1 \\
2 \\
3 \\
4 \\
5 \\
6 \\
7 \\
8 \\
9 \\
10 \\
11 \\
12 \\
13 \\
14 \\
15 \\
16 \\
17 \\
\text { Mean } \\
\text { SD }\end{array}$ & $\begin{array}{l}80 \\
60 \\
61 \\
68 \\
67 \\
62 \\
80 \\
82 \\
93 \\
60 \\
66 \\
62 \\
66 \\
67 \\
60 \\
75 \\
78 \\
70 \\
10\end{array}$ & $\begin{array}{r}137 \\
120 \\
122 \\
115 \\
122 \\
117 \\
130 \\
139 \\
150 \\
120 \\
130 \\
129 \\
120 \\
141 \\
136 \\
139 \\
138 \\
130 \\
10\end{array}$ & $\begin{array}{r}120 \\
123 \\
180 \\
162 \\
216 \\
125 \\
132 \\
116 \\
134 \\
150 \\
170 \\
126 \\
128 \\
101 \\
150 \\
115 \\
110 \\
139 \\
29\end{array}$ & $\begin{array}{r}116 \\
124 \\
158 \\
153 \\
200 \\
128 \\
137 \\
129 \\
136 \\
158 \\
133 \\
120 \\
128 \\
102 \\
174 \\
115 \\
113 \\
137 \\
25\end{array}$ & $\begin{array}{r}87 \\
84 \\
120 \\
106 \\
131 \\
73 \\
71 \\
84 \\
82 \\
76 \\
85 \\
84 \\
68 \\
60 \\
92 \\
82 \\
80 \\
86 \\
18\end{array}$ & $\begin{array}{r}85 \\
109 \\
108 \\
96 \\
98 \\
82 \\
63 \\
96 \\
56 \\
88 \\
83 \\
84 \\
100 \\
48 \\
122 \\
76 \\
70 \\
86 \\
19\end{array}$ & $\begin{array}{r}7.4 \\
6.0 \\
8.0 \\
9.3 \\
0.0 \\
7.9 \\
4.3 \\
4.0 \\
3.2 \\
6.9 \\
1.8 \\
8.5 \\
5.1 \\
5.0 \\
13.0 \\
2.9 \\
2.8 \\
5.6 \\
3.2\end{array}$ & $\begin{array}{r}6.3 \\
7.4 \\
7.3 \\
5.4 \\
1.0 \\
9.3 \\
6.0 \\
6.0 \\
2.0 \\
6.2 \\
4.0 \\
7.6 \\
11.8 \\
9.1 \\
13.7 \\
8.1 \\
3.7 \\
6.7 \\
3.2\end{array}$ & $\begin{array}{r}13 \\
11 \\
18 \\
20 \\
23 \\
14 \\
22 \\
16 \\
12 \\
24 \\
15 \\
17 \\
18 \\
12 \\
28 \\
12 \\
20 \\
17 \\
5\end{array}$ & $\begin{array}{r}9 \\
9 \\
12 \\
11 \\
8 \\
10 \\
13 \\
11 \\
12 \\
15 \\
7 \\
10 \\
13 \\
10 \\
20 \\
9 \\
7 \\
11 \\
3\end{array}$ & $\begin{array}{r}51.6 \\
46.5 \\
50.6 \\
47.7 \\
37.8 \\
49.8 \\
37.4 \\
41.3 \\
32.5 \\
45.4 \\
38.4 \\
48.0 \\
45.1 \\
43.9 \\
52.6 \\
40.5 \\
50.0 \\
44.6 \\
5.8\end{array}$ & $\begin{array}{r}41.2 \\
44.9 \\
44.5 \\
35.1 \\
31.3 \\
47.4 \\
41.0 \\
40.3 \\
28.6 \\
40.6 \\
35.9 \\
41.6 \\
45.4 \\
40.0 \\
43.4 \\
40.8 \\
36.3 \\
39.9 \\
5.0\end{array}$ & $\begin{array}{r}1,400 \\
2,000 \\
1,350 \\
1,200 \\
2,050 \\
1,600 \\
1,780 \\
1,300 \\
2,000 \\
1,500 \\
2,700 \\
1,700 \\
1,400 \\
1,600 \\
1,700 \\
1,500 \\
1,400 \\
1,660 \\
370\end{array}$ & $\begin{array}{r}1,300 \\
2,400 \\
1,400 \\
1,800 \\
2,650 \\
1,900 \\
2,240 \\
1,900 \\
2,600 \\
2,250 \\
2.800 \\
2,400 \\
1,700 \\
1,850 \\
2,200 \\
1,950 \\
1,800 \\
2,070 \\
420\end{array}$ & $\begin{array}{r}1,350 \\
1,390 \\
1,430 \\
1,800 \\
2,250 \\
1,575 \\
1,400 \\
1,880 \\
2,150 \\
2,000 \\
1,930 \\
1,470 \\
1,560 \\
1,480 \\
1,920 \\
1,800 \\
1,480 \\
1,700 \\
290\end{array}$ & $\begin{array}{r}1,800 \\
1,450 \\
1,610 \\
2,400 \\
2,400 \\
1,750 \\
1,470 \\
1,920 \\
2,820 \\
2,200 \\
1,600 \\
1,390 \\
1,940 \\
1,440 \\
2,720 \\
1,840 \\
1,640 \\
1,900 \\
450\end{array}$ \\
\hline$p$ & \multicolumn{2}{|c|}{$<10^{-8}$} & \multicolumn{2}{|c|}{ NS } & \multicolumn{2}{|c|}{ NS } & \multicolumn{2}{|c|}{ NS } & & & \multicolumn{2}{|c|}{$<10^{-3}$} & \multicolumn{2}{|c|}{$<10^{-5}$} & \multicolumn{2}{|c|}{$<0.01$} \\
\hline
\end{tabular}

$\mathrm{dP} / \mathrm{dt}=$ peak rate of change of pressure; EDP = end-diastolic pressure; ESP = pressure at peak negative $\mathrm{dP} / \mathrm{dt} ; \mathrm{HR}=\mathrm{heart}$ rate; $\mathrm{NS}=\mathrm{not}$ significant; $p=$ probability that difference in mean values between $R$ and $P$ occurs by chance; $P=$ paced heart rate; $P k S P=$ peak systolic pressure; Pmin = minimal diastolic pressure; $R=$ resting heart rate; $S D=$ standard deviation; $T=$ time constant of relaxation. 
Thus, all hemodynamic measurements apply directly to the beat analyzed for ventriculography. The electrocardiogram, left ventricular pressure and its first derivative and the film frame markers were recorded during angiography at a paper speed of $200 \mathrm{~mm} / \mathrm{s}$.

Definitions: Isovolumic relaxation phase was defined as the period between the peak negative rate of change of pressure and the opening of the mitral valve (Fig. 1). This definition differs slightly from the conventional definition of the isovolumic relaxation phase-which is measured starting with closure of the aortic valve. Our definition was chosen because it provided the closest approximation of this period in light of simultaneous the unavailability of aortic pressure data and because it assured a more accurate exponential fit to the decrease in pressure.

The rate of relaxation was quantified by the time constant of pressure decay according to the method of Weiss, et al. ${ }^{10}$ using a least squares fit to the logarithm of pressure. Opening of the mitral valve was defined from the angiographic frame preceding that in which nonopacified blood first entered the left ventricle. In all cases included in the study the opening of the mitral valve was recognized in the same frame by two independent observers.

Early diastole was defined as the interval between the opening of the mitral valve and minimal ventricular diastolic pressure. This is the pressure at which the rate of change of pressure first reaches 0 (Fig. 1). Early diastolic left ventricular inflow volume was measured as an absolute value $(\mathrm{ml})$ and as percent of total filling. Early diastolic mean inflow rate was measured as the ratio between the difference of ventricular volumes at minimal pressure and opening of the mitral valve and the time interval corresponding to the number of frames between them. Left ventricular inflow volume and rate were normalized for ventricular volume at minimal diastolic pressure.

Statistical analysis was performed with the Student's $t$ test for paired data and with linear regression analysis, where appropriate.

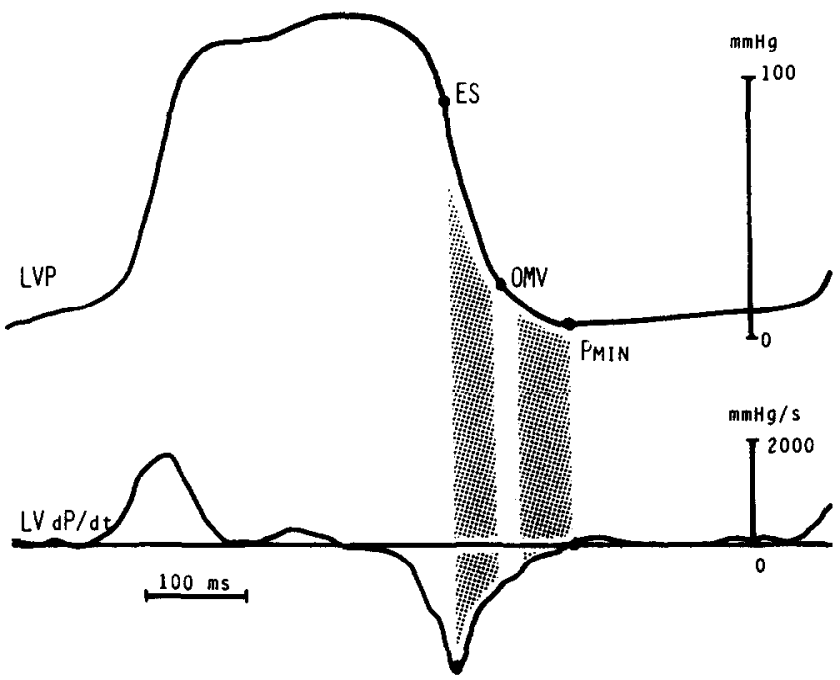

FIGURE 1. The isovolumic relaxation, as defined by left ventricular pressure (LVP), occurs after end-systole (ES) between peak negative rate of change of left ventricular pressure (LV dP/dt) and the opening of the mitral valve (OMV). Early diastole is defined as the interval between the opening of the mitral valve and left ventricular minimal diastolic pressure $\left(P_{M I N}\right)$, where the rate of change of pressure $(\mathrm{dP} / \mathrm{dt})$ equals 0 .

\section{Results}

The hemodynamic and cineangiographic measurements at rest and during cardiac pacing are shown in Tables II to IV. During pacing heart rate was increased from $69 \pm 9$ (mean \pm standard deviation) to $129 \pm 10$ beats/min in increments of 10 to 20 beats/min every 2 minutes.

\section{TABLE III}

Left Ventricular Volume Measurements and Derived Indexes

\begin{tabular}{|c|c|c|c|c|c|c|c|c|c|c|c|c|c|c|c|c|c|c|c|}
\hline \multirow[b]{2}{*}{ Case } & \multirow[b]{2}{*}{$\operatorname{BSA}\left(\mathrm{m}^{2}\right)$} & \multicolumn{2}{|c|}{$\begin{array}{l}\text { EDV } \\
(\mathrm{ml})\end{array}$} & \multicolumn{2}{|c|}{$\begin{array}{l}\text { ESV } \\
\text { (ml) }\end{array}$} & \multicolumn{2}{|c|}{$\begin{array}{l}\text { EF } \\
(\%)\end{array}$} & \multicolumn{2}{|c|}{$\begin{array}{c}V \min \\
(\mathrm{ml})\end{array}$} & \multicolumn{2}{|c|}{$\begin{array}{l}\text { EDl } \\
(\mathrm{ml})\end{array}$} & \multicolumn{2}{|c|}{$\begin{array}{c}\text { EDI/Vmin } \\
(\%)\end{array}$} & \multicolumn{2}{|c|}{$\begin{array}{l}\text { FEDI } \\
(\%)\end{array}$} & \multicolumn{2}{|c|}{$\begin{array}{l}\text { EDIR } \\
(\mathrm{ml} / \mathrm{s})\end{array}$} & \multicolumn{2}{|c|}{$\begin{array}{c}\text { EDIR/Vmin } \\
\left(s^{-1}\right)\end{array}$} \\
\hline & & R & $P$ & $\mathbf{R}$ & $\mathbf{P}$ & $\mathbf{R}$ & $\mathbf{P}$ & $\mathbf{R}$ & $\mathbf{P}$ & $\mathbf{R}$ & $\mathbf{P}$ & $\mathbf{R}$ & $\mathbf{P}$ & $\mathbf{R}$ & $\mathbf{P}$ & $\mathbf{R}$ & $\mathbf{P}$ & $\mathbf{R}$ & $\mathbf{P}$ \\
\hline $\begin{array}{c}1 \\
2 \\
3 \\
4 \\
5 \\
6 \\
7 \\
8 \\
9 \\
10 \\
11 \\
12 \\
13 \\
14 \\
15 \\
16 \\
17 \\
\text { Mean } \\
\text { SD } \\
\text { p } \\
\end{array}$ & $\begin{array}{l}2.00 \\
1.93 \\
1.70 \\
2.02 \\
1.75 \\
1.76 \\
1.82 \\
1.73 \\
1.64 \\
1.99 \\
1.81 \\
2.05 \\
1.85 \\
1.83 \\
1.80 \\
1.86 \\
1.82\end{array}$ & $\begin{array}{r}126 \\
159 \\
182 \\
184 \\
129 \\
194 \\
200 \\
215 \\
139 \\
290 \\
206 \\
186 \\
210 \\
180 \\
149 \\
175 \\
229 \\
185 \\
40\end{array}$ & $\begin{array}{r}91 \\
120 \\
128 \\
158 \\
93 \\
146 \\
160 \\
189 \\
111 \\
216 \\
118 \\
122 \\
160 \\
110 \\
96 \\
124 \\
177 \\
136 \\
36\end{array}$ & $\begin{array}{r}68 \\
67 \\
8 \\
8 \\
5 \\
73 \\
7 \\
11 \\
35 \\
127 \\
55 \\
7 \\
95 \\
45 \\
56 \\
63 \\
98 \\
74 \\
25\end{array}$ & $\begin{array}{r}41 \\
50 \\
79 \\
75 \\
42 \\
53 \\
65 \\
112 \\
45 \\
123 \\
28 \\
52 \\
93 \\
49 \\
39 \\
53 \\
13 \\
60 \\
29 \\
007\end{array}$ & $\begin{array}{l}52 \\
60 \\
54 \\
56 \\
58 \\
62 \\
63 \\
47 \\
72 \\
56 \\
73 \\
62 \\
53 \\
73 \\
62 \\
64 \\
57 \\
60 \\
7 \\
<0 \\
\end{array}$ & $\begin{array}{r}55 \\
58 \\
38 \\
53 \\
55 \\
64 \\
59 \\
41 \\
59 \\
43 \\
75 \\
58 \\
42 \\
55 \\
59 \\
57 \\
59 \\
55 \\
9 \\
003 \\
\end{array}$ & $\begin{array}{r}74 \\
92 \\
106 \\
118 \\
74 \\
100 \\
117 \\
159 \\
62 \\
169 \\
100 \\
88 \\
131 \\
69 \\
71 \\
86 \\
143 \\
103 \\
32\end{array}$ & $\begin{array}{r}77 \\
108 \\
111 \\
114 \\
65 \\
98 \\
114 \\
159 \\
70 \\
167 \\
94 \\
99 \\
146 \\
95 \\
80 \\
105 \\
135 \\
108 \\
30\end{array}$ & $\begin{array}{r}12 \\
15 \\
5 \\
19 \\
19 \\
21 \\
34 \\
36 \\
18 \\
31 \\
27 \\
11 \\
26 \\
15 \\
15 \\
20 \\
40 \\
21 \\
10 \\
<1\end{array}$ & $\begin{array}{l}25 \\
46 \\
24 \\
30 \\
21 \\
30 \\
43 \\
46 \\
20 \\
31 \\
62 \\
42 \\
45 \\
42 \\
37 \\
49 \\
59 \\
38 \\
12 \\
-4\end{array}$ & $\begin{array}{r}16 \\
16 \\
5 \\
16 \\
26 \\
21 \\
29 \\
21 \\
29 \\
18 \\
27 \\
13 \\
20 \\
22 \\
21 \\
23 \\
28 \\
21 \\
6 \\
<1 \\
\end{array}$ & $\begin{array}{l}32 \\
43 \\
22 \\
26 \\
32 \\
31 \\
38 \\
27 \\
29 \\
19 \\
66 \\
42 \\
31 \\
44 \\
46 \\
47 \\
43 \\
36 \\
11 \\
0-5\end{array}$ & $\begin{array}{r}17 \\
16 \\
7 \\
17 \\
24 \\
18 \\
29 \\
42 \\
18 \\
21 \\
19 \\
10 \\
25 \\
12 \\
16 \\
19 \\
33 \\
20 \\
8\end{array}$ & $\begin{array}{l}64 \\
79 \\
71 \\
42 \\
34 \\
41 \\
72 \\
70 \\
50 \\
40 \\
71 \\
66 \\
78 \\
69 \\
66 \\
70 \\
67 \\
61 \\
14\end{array}$ & $\begin{array}{l}20 \\
25 \\
11 \\
31 \\
39 \\
35 \\
70 \\
60 \\
30 \\
64 \\
56 \\
27 \\
43 \\
25 \\
25 \\
25 \\
50 \\
37 \\
17\end{array}$ & $\begin{array}{r}416 \\
575 \\
342 \\
833 \\
350 \\
750 \\
706 \\
1150 \\
500 \\
645 \\
861 \\
525 \\
562 \\
525 \\
616 \\
612 \\
983 \\
644 \\
218\end{array}$ & $\begin{array}{l}2.6 \\
2.7 \\
1.1 \\
2.6 \\
5.3 \\
3.5 \\
6.0 \\
3.5 \\
4.8 \\
3.8 \\
5.6 \\
3.1 \\
3.3 \\
3.6 \\
3.5 \\
2.9 \\
3.5 \\
3.6 \\
1.2 \\
<10\end{array}$ & $\begin{array}{l}5.4 \\
5.3 \\
3.0 \\
7.3 \\
5.3 \\
7.6 \\
6.1 \\
6.8 \\
7.1 \\
3.8 \\
9.1 \\
5.3 \\
3.8 \\
6.5 \\
7.7 \\
5.8 \\
7.1 \\
6.0 \\
1.6 \\
0^{-5} \\
\end{array}$ \\
\hline
\end{tabular}

$\mathrm{BSA}=$ body surface area; $\mathrm{EDI}=$ early diastolic inflow volume, $\mathrm{EDIR}=$ early diastolic inflow rate; $\mathrm{EDV}=$ end-diastolic volume; $\mathrm{EF}=$ ejection fraction; ESV = end-systolic volume; FEDI = early dlastolic inflow volume as the fraction of total filling; $p=$ probabillty by paired $t$ test; $P=$ paced heart rate; $\mathrm{R}=$ resting heart rate; $\mathrm{SD}=$ standard deviation; $\mathrm{Vmin}=$ volume at minimal left ventricular diastolic pressure. 


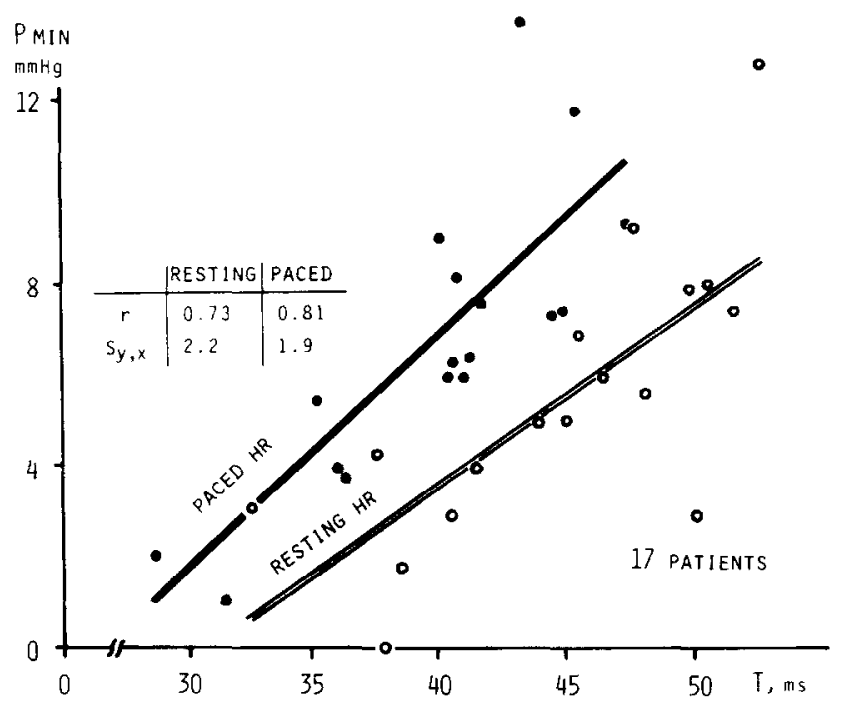

FIGURE 2. Left ventricular minimal pressure $\left(P_{\text {MiN }}\right)$ versus the time constant of relaxation of isovolumic pressure decay ( $T$ ) at resting (open clrcles) and paced (solld clrcles) heart rates (HR). $P_{\text {MIN }}$ and T are significantly correlated in both conditions. The regression line shifts slightly toward increased $P_{\text {MIN }}$ during pacing, although the mean value of $P_{M I N}$ is unchanged. $r=$ correlation coefficient; $S_{y, x}=$ standard error of the estimate.

Hemodynamic data (Table II): Left ventricular peak systolic, end-systolic (at peak negative rate of change of pressure) and minimal diastolic pressure did not change significantly during pacing, but ventricular end-diastolic pressure decreased significantly (probability $[\mathrm{p}]<10^{-6}$ ) from $17 \pm 5$ to $11 \pm 3 \mathrm{~mm} \mathrm{Hg}$. In this group of patients with submaximal pacing, end-diastolic pressure was not observed to increase in any case with pacing. The time constant of relaxation also decreased significantly $\left(p<10^{-3}\right)$ from $44.6 \pm 5.8$ to $39.9 \pm 5.0 \mathrm{~ms}$ and was significantly correlated with minimal diastolic pressure at resting $\left(r=0.75, p<10^{-3}\right)$ and paced heart rates $\left(\mathrm{r}=0.81, \mathrm{p}<10^{-4}\right)$ (Fig. 2). All but one patient showed an increase in peak positive rate of change of pressure $\left(1,660\right.$ versus $\left.2,070 \mathrm{~mm} \mathrm{Hg} / \mathrm{s}, \mathrm{p}<10^{-5}\right)$. Peak negative rate of change of pressure showed a less dramatic increase $(1,700$ versus $1,900 \mathrm{~mm} \mathrm{Hg} / \mathrm{s}, \mathrm{p}<0.01)$, with two patients showing a measurable decrease in this quantity. 'The contraction phase variables were largely uncorrelated with the relaxation phase variables.

Cineangiographic data (Table III): During tachycardia the left ventricular end-diastolic volume decreased from $185 \pm 40$ to $136 \pm 36 \mathrm{ml}$, in parallel with the decrease of end-diastolic pressure. The end-systolic volume decreased less than end-diastolic volume, with a consequent decrease in ejection fraction from 60 to 55 percent $(p<0.003)$. The left ventricular early diastolic inflow volume increased from $21 \pm 10$ to $38 \pm 12 \mathrm{ml}$, nearly doubling during tachycardia, and the fraction of total ventricular filling occurring in early diastole increased even more, from 20 to 61 percent (Fig. 3). Also, the mean early diastolic inflow rate increased significantly from 377 to $644 \mathrm{ml} / \mathrm{s}\left(\mathrm{p}<10^{-5}\right)$. When ventricular inflow volume and inflow rate were normalized for volume at minimal diastolic pressure, they were significantly correlated with the time constant of relaxation at resting heart rate $(\mathrm{r}=-0.64, \mathrm{p}<0.005$ and $\mathrm{r}=$ $-0.72, p<0.009$ ) (Fig. 4 and 5). However, during

TABLE IV

Diastolic Time Intervals

\begin{tabular}{|c|c|c|c|c|c|c|c|c|c|}
\hline \multirow[b]{2}{*}{ Case } & \multicolumn{2}{|c|}{$\begin{array}{c}t_{1} \\
\text { (ms) }\end{array}$} & \multicolumn{2}{|c|}{$\begin{array}{c}\mathrm{t}_{2} \\
(\mathrm{~ms})\end{array}$} & \multirow{2}{*}{$\begin{array}{c}t_{3} \\
(\mathrm{~ms}) \\
P\end{array}$} & \multicolumn{2}{|c|}{$t_{1}+t_{2} / T$} & \multirow{2}{*}{$\begin{array}{c}t_{1}+t_{2} \\
+t_{3} / T \\
P\end{array}$} & \multirow{2}{*}{$\begin{array}{c}\text { Pacing Spike } \\
\text { to Pmin } \\
\text { (ms) } \\
P\end{array}$} \\
\hline & $\mathrm{R}$ & $\mathrm{P}$ & $R$ & $P$ & & $R$ & $P$ & & \\
\hline $\begin{array}{c}1 \\
2 \\
3 \\
4 \\
5 \\
6 \\
7 \\
8 \\
9 \\
10 \\
11 \\
12 \\
13 \\
14 \\
15 \\
16 \\
17 \\
\text { Mean } \\
\text { SD } \\
\text { p }\end{array}$ & $\begin{array}{l}60 \\
80 \\
84 \\
84 \\
48 \\
80 \\
48 \\
60 \\
40 \\
48 \\
60 \\
80 \\
60 \\
60 \\
60 \\
40 \\
40 \\
61 \\
15\end{array}$ & $\begin{array}{l}60 \\
60 \\
56 \\
60 \\
48 \\
60 \\
36 \\
60 \\
40 \\
36 \\
60 \\
60 \\
40 \\
20 \\
40 \\
20 \\
40 \\
47 \\
14\end{array}$ & $\begin{array}{l}60 \\
60 \\
42 \\
60 \\
48 \\
60 \\
48 \\
50 \\
50 \\
48 \\
48 \\
40 \\
60 \\
60 \\
60 \\
80 \\
80 \\
56 \\
11\end{array}$ & $\begin{array}{l}60 \\
80 \\
70 \\
36 \\
60 \\
40 \\
60 \\
40 \\
40 \\
48 \\
72 \\
80 \\
80 \\
80 \\
60 \\
80 \\
60 \\
61 \\
16\end{array}$ & $\begin{array}{r}20 \\
100 \\
70 \\
120 \\
60 \\
100 \\
50 \\
40 \\
40 \\
84 \\
72 \\
50 \\
80 \\
60 \\
40 \\
40 \\
40 \\
63 \\
27\end{array}$ & $\begin{array}{l}2.3 \\
3.0 \\
2.4 \\
3.0 \\
2.5 \\
2.8 \\
2.5 \\
2.9 \\
3.0 \\
2.1 \\
3.3 \\
2.5 \\
2.6 \\
2.7 \\
2.2 \\
2.9 \\
2.4 \\
2.7 \\
0.3\end{array}$ & $\begin{array}{l}2.9 \\
3.1 \\
2.8 \\
2.9 \\
4.0 \\
2.1 \\
2.3 \\
2.4 \\
2.8 \\
2.3 \\
3.6 \\
3.3 \\
2.6 \\
2.5 \\
2.3 \\
2.4 \\
2.7 \\
2.8 \\
0.5\end{array}$ & $\begin{array}{l}3.4 \\
4.9 \\
4.8 \\
6.1 \\
5.7 \\
3.9 \\
4.8 \\
3.4 \\
4.2 \\
4.1 \\
5.6 \\
4.8 \\
4.4 \\
4.0 \\
3.3 \\
3.4 \\
3.8 \\
4.4 \\
0.9\end{array}$ & $\begin{array}{r}240 \\
260 \\
320 \\
120 \\
150 \\
175 \\
235 \\
235 \\
300 \\
285 \\
335 \\
400 \\
235 \\
240 \\
225 \\
190 \\
175 \\
242 \\
71\end{array}$ \\
\hline
\end{tabular}

NS = not significant; $p=$ probability; $P=$ paced heart rate $R=$ resting heart rate: $S D=$ standard deviation; $T=$ time constant of relaxation: $t_{1}=$ time interval between peak negative $\mathrm{dP} / \mathrm{dt}$ and opening of the mitral valve; $t_{2}=$ time interval between opening of the mitral valve and minimal diastolic pressure; $t_{3}=$ time interval between $P \min$ and end-diastole. 
tachycardia these correlations failed to achieve significance.

Time intervals (Table IV): The time of occurrence of minimal diastolic pressure as expressed in time constants of relaxation after peak negative rate of change of pressure was not different at resting and paced heart rates and was, respectively, 2.7 and 2.8 times the time constant. During tachycardia minimal diastolic pressure preceded end-diastole, which occurred on average 4.3 time constants after the pcak negative rate of change of pressure. During tachycardia, first degree atrioventricular block developed in all patients, and the interval between the electrical spike and minimal diastolic pressure was $242 \pm 71 \mathrm{~ms}$.

\section{Discussion}

The relations between ventricular relaxation and filling have been studied extensively in animals, ${ }^{11-15}$ but barely explored in human beings. Burch et al., ${ }^{16}$ by plotting pressure-volume loops, first showed in human subjects that during early diastole the left ventricle fills while the pressure is still decreasing. This finding was later described by Dodge et al..$^{17}$ and more recently by others. ${ }^{2,3,5}$

Distribution and dynamics of left ventricular filling: In our patients the duration of early diastole at resting heart rate averaged $56 \mathrm{~ms}$ and during this time 20 percent of total filling took place (range 7 to 42 percent). This finding is consistent with the finding of 24 percent reported by Yellin et al., ${ }^{4}$ who measured the transmitral flow with electromagnetic probes sutured

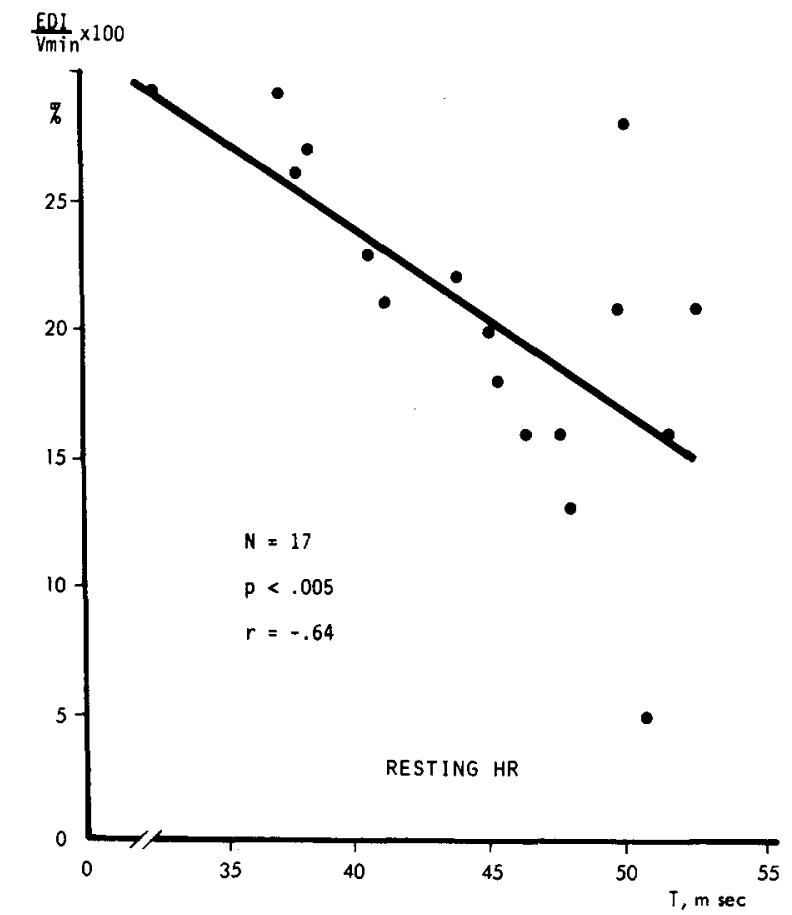

FIGURE 4. Left ventricular early diastolic inflow volume (EDI) normalized for volume (Vmin) at minimal diastolic pressure versus the time constant of isovolumic pressure decay (T) at resting heart rate (HR).

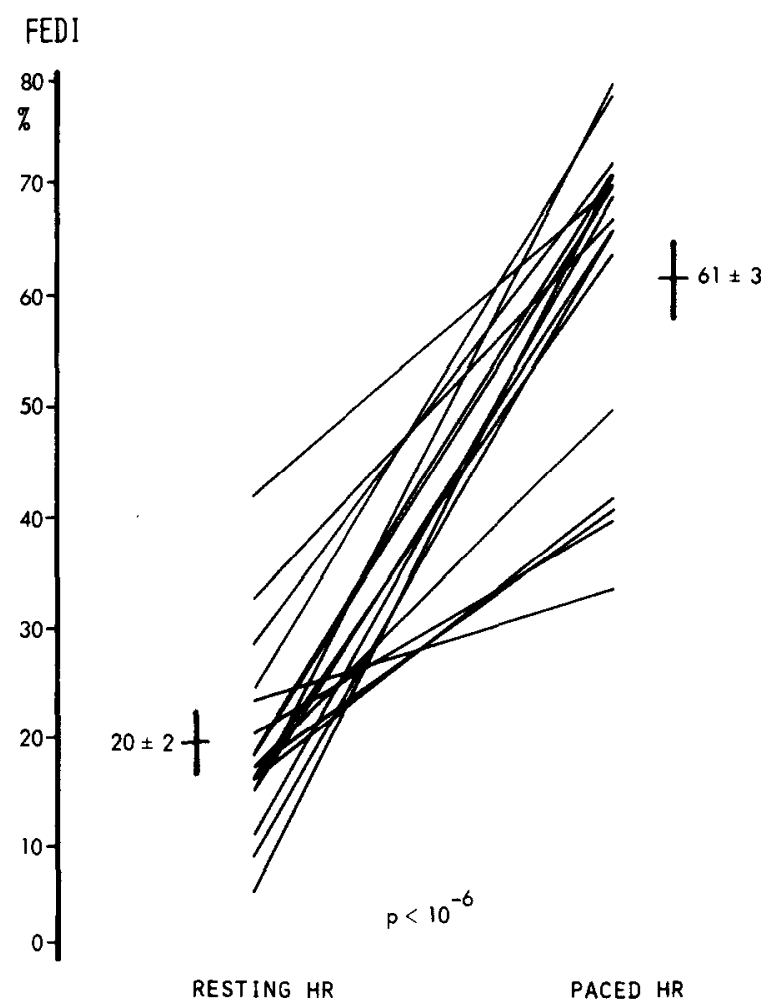

FIGURE 3. Early diastolic left ventricular inflow volume as percent of total filling (FEDI) at resting and paced heart rates (HR). In all 17 patients it increased significantly during pacing.

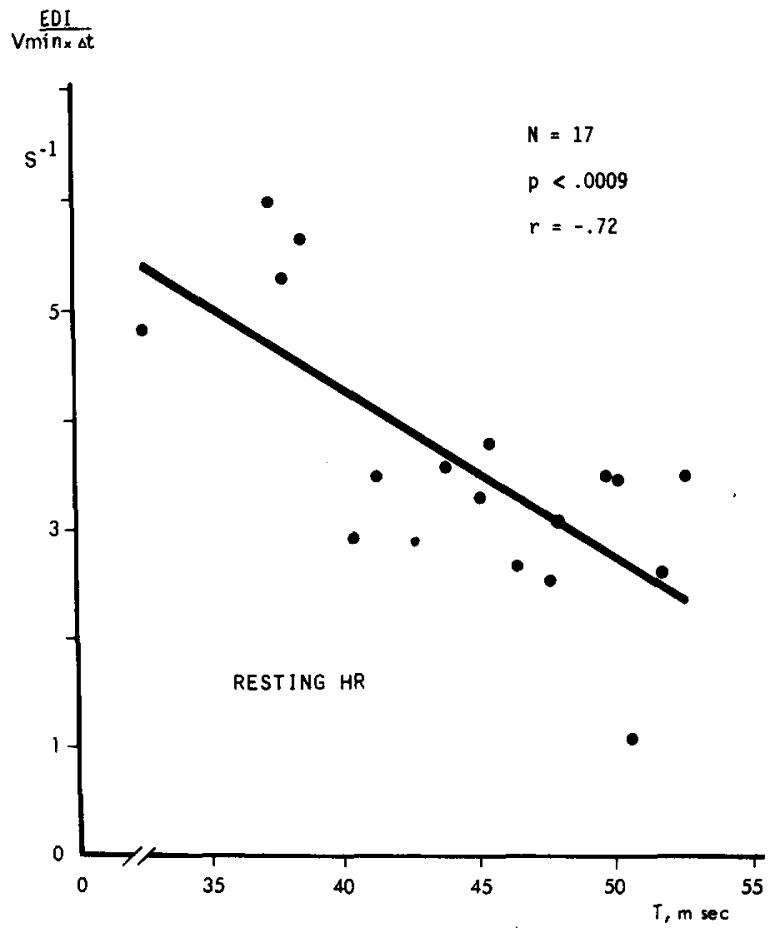

FIGURE 5. Left ventricular mean early diastolic inflow rate normalized for volume at minimal diastolic pressure (EDI $/ V \min \times \Delta t$ ) versus the time constant of isovolumic pressure decay (T) at resting heart rate (HR). 
to the mitral ring in open chest dogs. In human subjects there are few data available obtained with cineangiographic measurements. ${ }^{3,5}$ These data show somewhat higher values for the percent of early diastolic filling: an average of 39 percent in 16 cases $^{5}$ and a range from 7 to 62 percent in 17 cases. ${ }^{18}$ However, the data in these two series are not fully comparable with ours, because of the nonhomogeneous patient population, which included normal subjects and those with cardiomyopathy, coronary artery disease and valvular heart disease. Furthermore, Alderman et al. ${ }^{5}$ did not measure pressure and volume simultaneously, did not use tip manometry in the majority of cases and utilized a slower film speed (30 frames/s).

Our results obtained during submaximal tachycardia show that the different heart rates are accompanied by important changes in the distribution and the dynamics of left ventricular filling. The large increase in the fraction of total filling during early diastole from 20 to 62 percent is explained not only by a shortening of filling time and reduction in end-diastolic volume, but also by a concomitant, almost twofold increase in early diastolic inflow volume from 21 to $38 \mathrm{ml}$. The inflow rate also showed a large increase from 3.6 to $6 \mathrm{~s}^{-1}$. These data further confirm the difficulty in measuring compliance at high heart rates and rule out a simple passive elastic model for the left ventricle for the entire diastolic period. $4,5,18-21$

The extension of left ventricular relaxation to the filling phase has recently been studied in animals. ${ }^{6,7} \mathrm{In}$ a canine right heart bypass preparation, ${ }^{6}$ left ventricular relaxation extended up to an average of 2.9 time constants of relaxation (range 2.5 to 3.5) after the peak negative rate of change of pressure. These findings are similar to the average intervals from the peak negative rate of change of pressure to minimal diastolic pressure that we report of 2.7 and 2.8 time constants, respectively, at resting and paced heart rates. Admittedly, minimal diastolic pressure does not necessarily correspond to the termination of relaxation, but represents the crossover point between left ventricular relaxation and filling, two processes with opposite effects on filling pressure. However, when ventricular isovolumic pressure is extrapolated to the time of occurrence of minimal diastolic pressure, then minimal diastolic pressure would be calculated from $\mathrm{e}^{-2.7}=0.07$ and $\mathrm{e}^{-2.8}=0.06$ of the initial value of pressure at peak negative rate of change of pressure; that is, relaxation is essentially completed.

There remains little consensus on the biophysical model for relaxation of the myocardium, but most studies demonstrate an exponential decline in left ventricular pressure. Work on monolayer cell cultures ${ }^{22}$ has revealed the existence of two phases of relaxation associated with calcium uptake by the sarcoplasmic reticulum (relaxation time $=33 \mathrm{~ms}$ ) and possibly calcium extrusion through a sodium-calcium exchange mechanism (relaxation time $=48 \mathrm{~ms}$ ). Recent studies in dogs have also revealed a dual time-constant relaxation process, but this has been ascribed to a provoked (coronary ligation) asynchronous relaxation, in which there was an increase in time constant, rather than to a more fundamental biochemical process. ${ }^{23,24}$ However, most studies in intact animals and human beings have reported a monoexponential process, ${ }^{10}$ and indeed Kumada et al..$^{23}$ found that the two phases of relaxation merge into one when there is synchronous relaxation. During submaximal pacing we found no evidence of induced ischemia as deduced from the presence of pain, important electrocardiographic changes or induced abnormalities in regional wall motion. The time constant of relaxation increased measurably during pacing in only one patient (Case 7), and he was the only one whose ventriculogram revealed an akinetic segment. For the entire group the time constant of relaxation decreased from 45 to $40 \mathrm{~ms}$.

Extension of relaxation into early diastole: Several observations suggest that left ventricular relaxation is a relevant determinant of early diastolic filling pressure. First, a significant positive correlation has been found between the time constant of relaxation and minimal diastolic pressure at both resting and paced heart rates. Second, the actual average minimal diastolic pressures of 5.6 and $6.7 \mathrm{~mm} \mathrm{Hg}$ at resting and paced heart rates, respectively, are not significantly different from the theoretical values of 6.0 and $5.1 \mathrm{~mm} \mathrm{Hg} \mathrm{ob-}$ tained by extrapolating the exponential left ventricular pressure decay in the isovolumic phase to the timing of occurrence of minimal diastolic pressure. From these results we speculate that left ventricular viscoelastic properties, which are expected to result in increased pressure in early diastole for an elevated inflow rate,, $25-28$ are overshadowed by relaxation processes.

Role of atrial contraction: That the filling during early diastole is also influenced by left ventricular relaxation is also corroborated by the inverse correlation between the time constant of relaxation and left ventricular normalized inflow volume and inflow rate (Fig. 5 and 6). During tachycardia, the time constant of relaxation decreased and inflow volume and rate increased, but they were no longer significantly correlated at the highest paced rate. We believe that the link between relaxation and filling is interrupted because of the superimposition of atrial contraction on early diastole, as indicated by the time intervals (Table IV) between the atrial stimulation and minimal diastolic pressure. However, this remains speculative and there is no reported consensus about the relative role of relaxation (vis a fronte) and atrial contraction (vis a tergo) on the ventricular filling pattern during tachycardia. ${ }^{29-31}$

It is possible that, as an indirect result of the shortened diastolic filling period, atrial pressure became elevated during pacing, which would affect the inflow rate. However, our data revealed no significant change in minimal diastolic pressure and end-diastolic pressure actually decreased during pacing. More direct measurement of this effect could be obtained by transeptal measurement of atrial pressure or, less directly, of pulmonary wedge pressure. The former was considered contraindicated in these patients and the latter presents technical difficulties, especially during pacing. 
Implications: The foregoing results apply only to the group of patients studied, that is, those with coronary artery disease, and only over a pacing range not inducing ischemia. Although we found no evidence of ischemia, severe abnormalities in the contraction pattern or an elevation in ventricular end-diastolic pressure, findings that suggest that this group could be akin to a normal group, such an extrapolation of our results is unwarranted.
Our results confirm in human subjects the findings of previous experimental work in dogs that ventricular relaxation extends into the filling phase, affecting pressure-volume relations, and that this extension increases with tachycardia. Because relaxation can be affected independently from contractility $y^{32,33}$ and extends to a large part of diastole, more work is required to understand its pathophysiologic consequences on diastole and overall hemodynamics.

\section{References}

1. Whgers CJ. Cardiac mechanisms that limit operation of ventricular suction (abstr). Science 1957;126:1237.

2. McGavock PC, Baxley WA, Eddleman EE, Frimer M, Rackley CE. Left ventricular dimensions and dynamics of filling in patients with gallop heart sounds. Am J Med 1971;50:721-7.

3. Gaasch WH, Quinones MA, Cole JS. Left ventricular filling and diastolic pressure-volume relations in man (abstr). Clin Res 1974;:22:680A

4. Yellin E, Kennish A, Cowda R, Frater RW. A quantitative study of the volume inflow during ventricular relaxation determined by phasic transmitral flow measurements (abstr). Circulation 1974; 49:III-44.

5. Alderman EL, Glantz SA. Acute hemodynamic interventions shift the diastolic pressure-volume curve in man. Circulation 1976; 54:662-71.

6. Weisfeldt ML, Frederiksen JW, YIn FC, Welss JL. The time constant of left ventricular isovolumic fall predicts the effect of relaxation during diastolic filling (abstr). Clin Res 1977;25:262A.

7. Weisfeldt ML, Frederlksen JW, Yln FC, Woiss JL. Evidence of incomplete left ventricular relaxation in the dog. Prediction from the time constant for isovolumic pressure fall. $J$ Clin Invest 1978;62:1296-302.

8. Slager CJ, Relber JHC, Schuurblers JCH, Meester GT. Contouromat: a hard-wired left ventricular angio processing system. 1. Design and application. Comput Biomed Res 1978;11:491502.

9. Relber JHC, Slager CJ, Schuurbiers JCH, Meester GT. Contouromat: a hard-wired left ventricular angio processing system. II. Performance evaluation. Comput Biomed Res 1978;11:50323.

10. Weiss JL, Frederiksen JW, Welsfeldt ML. Hemodynamic determinants of the time-course of fall in canine left ventricular pressure. $\mathrm{J}$ Clin Invest 1976;58:751-60.

11. Katz $L N$. The role played by the ventricular relaxation process in filling the ventricle. Am J Physiol 1930;95:542-53.

12. Buckley NM, Ogden E, Linton DS. The effects of work load and heart rate on filling of the isolated right ventricle of the dog heart. Circ Res 1955;3:434-46.

13. Brecher GA. Critical review of recent work on ventricular diastolic suction. Circ Res 1958;6:554-66.

14. Tyberg JV, Keon WJ, Sonnenblick EM, Urschel CW. Mechanics of ventricular diastole. Cardiovasc Res 1970;4:423-8.

15. Kennish A, Yellin E, Frater RW. Dynamic stiffness profiles in the left ventricle. J Appl Physiol 1975;39:665-71.

16. Burch G, Ray CT, Cronvich GA. Certain mechanical peculiarities of the human cardiac pump in normal and diseased states. Circulation 1952;5:504-13.

17. Dodge HT, Hay RE, Sandler H. Pressure-volume characteristics of the diastolic left ventricle of man with heart disease. Am Heart
J 1962;64:503-11.

18. Gaasch WH, Levine HJ, Quinones MA, Alexander JK. Left ventricular compliance: mechanisms and clinical implications. Am J Cardiol 1976;38:645-53.

19. Fester A, Samet P. Passive elasticity of the human left ventricle: the "parallel elastic element." Circulation 1974;50:609-18.

20. Glantz SA. Ventricular pressure-volume curve indices change with end-diastolic pressure. Circ Res 1976;39:772-8.

21. Miraky I. Assessment of passive elastic stiffness of cardiac muscle: mathematical concepts, physiological and clinical considerations, directions of future research. Prog Cardiovasc Dis 1976;18: 277-308.

22. Miura DS, Bledert S, Smith TW, Barry WH. Evidence for two phases of relaxation in cultured ventricular cells (abstr). Circulation 1979;59:II-213.

23. Kumada T, Karliner JS, Pouleur H, Gallagher KP, Shirato K, Ross J. Effects of coronary occlusion on early ventricular diastolic events in conscious dogs. Am J Physiol 1979;237:H542-9.

24. Pouleur H, Karliner JS, Le Whiter MM, Covell JW. Diastolic viscous properties of the intact canine left ventricle. Circ Res 1979;45: 410-9.

25. Mitchell JH, Linden RJ, Sarnoff SJ. Influence of cardiac sympathetic and vagal nerve stimulation of the relation between left ventricular diastolic pressure and myocardial segmental length. Circ Res 1960;8:1100-7.

26. Noble MIM, Miline ENC, Joerke RJ, et al. Left ventricular filling and diastolic pressure-volume relations in the conscious dog. Circ Res 1969;24:269-83.

27. Rankin JS, Arentzen CE, McHale PA, Ling D, Anderson RW. Viscoelastic properties of the diastolic left ventricle in the conscious dog. Circ Res 1976;41:37-45.

28. Pouleur H, Karliner J, Le Winter H, Covell J. Nonlinearity of viscous resistance to stretch in the intact heart (abstr). Circulation 1978; 57:11-159.

29. Benchimol A. Significance of the contribution of atrial systole to cardiac function in man. Am J Cardiol 1969;23:568-71.

30. Nolan SP, Dlxon SH, Fisher OR, Monow AG. The influence of atrial contraction and mitral valve mechanics on ventricular filling. A study of instantaneous mitral valve flow in vivo. Am Heart $J$ 1969;77:784-91.

31. Hammermelster KE, Warbasse JA. The rate of change of left ventricular volume in man. II. Diastolic events in health and disease. Circulation 1974;49:739-47.

32. Parmley WW, Sonnenblick EH. Relation between mechanics of contraction and relaxation in mammalian cardiac muscle. Am J Physiol 1969;216:1084-91.

33. McLaurin LP, Rolett EL, Grossman W. Impaired left ventricular relaxation during pacing-induced ischemia. Am J Cardiol 1973; 32:751-7. 